
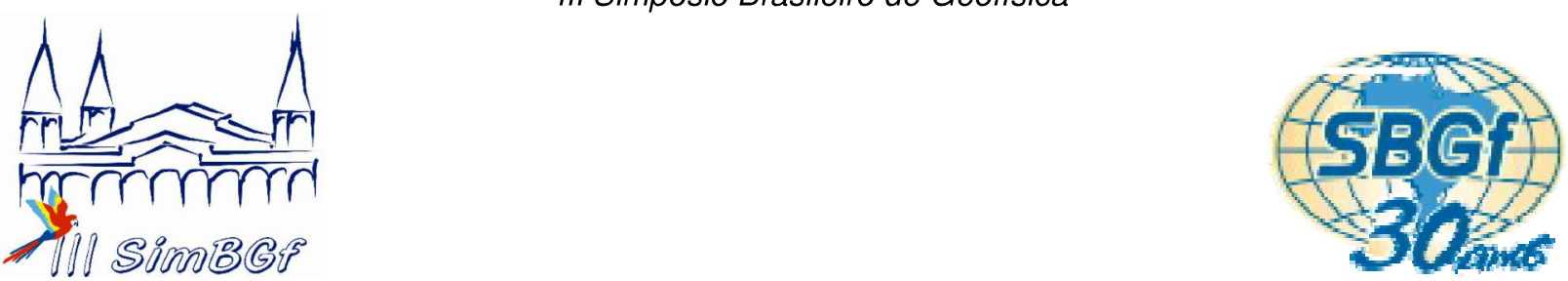

\title{
Investigando com GPR a planície litorânea de Barra do Jacuípe, litoral norte do Estado da Bahia
}

Daniel Carneiro Mello, Jacira C. B. Freitas, Marco A Barsottelli. Botelho - Universidade Federal da Bahia,CPGG/ IGEO, IF

Copyright 2008, SBGf - Sociedade Brasileira de Geofísica

Este texto foi preparado para a apresentação no III Simpósio Brasileiro de Geofísica, Belém, 26 a 28 de novembro de 2008. Seu conteúdo foi revisado pelo Comitê Técnico do III SimBGt, mas não necessariamente representa a opinião da SBGf ou de seus associados. E proibida a reprodução total ou parcial deste material para propósitos comerciais sem prévia autorização da SBGt.

\section{Resumo}

Neste trabalho utilizamos o método geofísico eletromagnético GPR (Ground Penetrating Radar) como ferramenta para a investigação da subsuperfície na região de Barra do Jacuípe, localizada no litoral norte do Estado da Bahia.

O levantamento de dados realizado no local utilizou uma única antena com freqüência central de $200 \mathrm{MHz}$ e com uma configuração de afastamento constante. Após o processamento dos dados, os radargramas gerados foram interpretados. Os resultados obtidos revelaram a estratigrafia costeira, onde as reflexões mostram os depósitos eólicos das areias litorâneas, a laguna ou zona de terra úmida, os depósitos de areia do cordão duna e a praia. Ë possível rastrear o refletor correspondente ao lençol freático até seu desaparecimento perto do oceano, causada pela cunha salina.

\section{Introdução}

O GPR (Ground Penetrating Radar) é uma técnica de mapeamento da sub superfície, baseada na detecção de ondas eletromagnéticas, as quais são transmitidas por uma fonte na superfície, propagam através da sub superfície, sendo refletidas e/ou difratadas de volta à superfície, onde são detectadas por uma antena receptora e armazenadas na seqüência de chegada na memória do equipamento de GPR. Este método tem ganhado força e aceitação em sua aplicabilidade, principalmente devido às suas facilidades operacionais, portabilidade dos equipamentos utilizados na aquisição dos dados, velocidade de execução dos ensaios, similaridades cinemáticas entre o comportamento das ondas sísmicas e eletromagnéticas, podendo fornecer informações precisas num curto período de tempo e ainda mantendo a integridade física dos sistemas investigados, servindo como uma avaliação geofísica não destrutiva.

O GPR apresenta boa discriminação e resolução por empregar freqüências acima de $10^{7} \mathrm{~Hz}$, contudo, sua utilização está condicionada à profundidade de penetração do sinal no solo, que é função das propriedades elétricas intrínsecas aos ambientes de investigação, principalmente da constante dielétrica e da condutividade elétrica.

As aplicações do GPR podem ser agrupadas em três linhas de pesquisa, as quais se diferenciam com base nas freqüências principais das antenas empregadas. $A$ primeira, nas aplicações geológicas, onde a profundidade de penetração tende a ser mais importante que uma resolução muito boa, onde são usadas antenas com freqüências menores ou iguais a $200 \mathrm{MHz}$; a segunda, são nos estudos geotécnicos, onde se procura detectar interferências como canos e tubos, no estudo do lastro e base de ferrovias, em investigações arqueológicas, ou no detalhamento da estratigrafia do solo (Ucha et al, 2002), onde antenas de 200 a $500 \mathrm{MHz}$ são as mais empregadas; a terceira linha está nas aplicações da engenharia ou em testes não destrutivos, onde mapeiase ferragens em estruturas de concreto armado bem como estuda a saúde do concreto, no estudo de capeamentos asfálticos, onde são usadas antenas com freqüências a partir de $700 \mathrm{MHz}$, tipicamente $900 \mathrm{MHz}$ até $1.5 \mathrm{GHz}$.

Em resumo, pode-se adotar como regra geral, o fato de que quanto maior a freqüência da fonte, maior será o efeito dispersivo na amplitude do sinal e menor será o comprimento de onda, acarretando em menores profundidades de investigação, contudo, fornecendo dados com maior resolução (Davis e Annan, 1989). Portanto, o GPR é ideal para ser aplicado em investigações rasas, tais como as citadas acima, podendo ainda acrescentar os estudos sobre contaminação do solo, vide Machado et al (2004); estudos hidro geológicos e no estudo de análogos de reservatórios de petróleo. Além disso, em situações favoráveis, pode também ser empregado em exploração mineral, vide Botelho (2008)

A aquisição deste trabalho foi realizada em Barra do Jacuípe, localizada no município de Camaçari entre as praias de Arembepe e Guarajuba, mais precisamente a $54 \mathrm{~km}$ de Salvador. Esta localidade é parte integrante do Litoral Norte do Estado da Bahia que possui aproximadamente uma extensão de $200 \mathrm{~km}$, compreendida entre o limite de Salvador e Lauro de Freitas, até a divisa do Estado com Sergipe, conforme ilustrado na Figura 1. Nessa porção da costa pode-se contemplar belíssimas praias, campos de dunas e restingas, recifes de corais, manguezais e inúmeras bacias de drenagem cortando a planície costeira. 


\section{Metodologia}

Os dados de GPR foram adquiridos com o equipamento SIR SYSTEM 2000 da GSSI utilizando uma antena com freqüência central de $200 \mathrm{MHz}$ em modo monoestático, com a configuração de afastamento constante. Esta configuração foi adotada na obtenção de todos os perfis registrados no local.

Foram realizadas duas campanhas de aquisições com a obtenção de 3 perfis na primeira e mais 4 perfis durante a segunda. Todos os dados foram processados no RADAN 6.5 (GSSI, 2005).

Durante as aquisições foi realizada a aplicação de ganhos, filtragens verticais e horizontais, com o objetivo de aperfeiçoar a qualidade das informações nos dados. Contudo, é importante salientar que neste préprocessamento de campo devem ser utilizados filtros com uma banda larga, de forma que dados potencialmente valiosos não sejam perdidos durante a fase de aquisição.

O objetivo do processamento, ao se aplicar técnicas de tratamento aos dados digitalizados, tem como intuito compensar a atenuação do sinal da fonte (transmissor), reposicionar refletores em suas posições corretas, corrigir distorções da imagem, etc, produzindo assim uma seção GPR final que realce, o mais fidedignamente possível, as estruturas geológicas de subsuperfície, facilitando a interpretação. Neste trabalho, as etapas de processamento consistiram na minimização das ondas diretas e aéreas dos dados; aplicação de ganhos variáveis aos dados; definição do tempo zero; filtragem no domínio da freqüência dos dados; análises de velocidade; deconvolução do pulso e migração.

A interpretação dos dados foi feita com base em estudos sobre a evolução geológica da região descritos na literatura e com base em informações orais fornecidas por professores experientes na geologia costeira do Estado da Bahia.

\section{Resultados}

A seção obtida na primeira aquisição (Figura 2 - Perfil 1.3) apresenta uma profundidade máxima de aproximadamente $13 \mathrm{~m}$. Podemos observar no radargrama correspondente a este perfil (Figura 3) a existência de três domínios distintos. O domínio logo abaixo do refletor de cor amarela que se encontra aproximadamente a uns $9 \mathrm{~m}$ de profundidade representa a Formação Barreiras, que é constituída de sedimentos areno-argilosos, inconsolidados, que repousam diretamente sobre o embasamento cristalino (Accioly, 1997). A deposição da Formação Barreiras ocorreu ao final do Plioceno (1,8 Ma) em ambiente de leques aluviais coalescentes, sob condições de clima semi-árido, durante uma fase de soerguimento continental (Ghignone, 1979).
Recobrindo o Barreiras, temos as areias pleistocênicas de origem eólica apresentando estratificações planoparalelas, representadas no radargrama pela cor branca. Imediatamente acima do refletor amarelo (topo do Barreiras) e por sobre o mesmo, podemos observar a ocorrência de um número grande de difrações que indica uma possível superfície erosional com vários corpos difratores na base do pacote de areia. Existe uma atenuação do sinal do radar abaixo da citada superfície erosional, ou seja, na Formação Barreiras, indicando que se trata de uma material areno-argiloso.

A seção obtida na segunda aquisição corresponde ao radargrama da Figura 4, apresentando uma profundidade máxima de aproximadamente $15 \mathrm{~m}$.

$\mathrm{Na}$ obtenção deste perfil, partimos do continente em direção ao mar, descendo uma elevação à qual corresponderia às areias litorâneas pleistocênicas de origem eólica (Martin et al, 1980) interpretadas no radargrama pelas linhas de cor branca. Associadas a essas areias podem ser observadas algumas reflexões. Logo abaixo dessa areia aparecem dois fortes refletores (cor amarela), estando o refletor mais raso em torno de 2 a $5 \mathrm{~m}$ e o mais profundo em torno de 7 a $12 \mathrm{~m}$ de profundidade, delimitando (topo e base) o que pode possivelmente ser o Barreiras.

Seguindo mais adiante, passamos por uma área pertencente a uma laguna (representada pela cor laranja), área esta conhecida como Terras úmidas, a qual pode ao longo do tempo estar inundada e/ou saturada por água superficial e/ou subterrânea, onde o nível do lençol freático (linha vermelha tracejada) está próximo ou à superfície do terreno, formando lagunas de água rasa, tal como foi encontrado no local. Esta zona baixa separa as areias litorâneas pleistocênicas (terraços marinhos pleistocênicos) das holocênicas (terraços marinhos holocênicos) (Martin et al, 1980). Esses terraços marinhos holocênicos caracterizam-se por depósitos pouco desenvolvidos dispostos paralelamente a atual linha de praia. Apresentam larguras variáveis, podendo ter desde 15 a $50 \mathrm{~m}$ de largura. As altitudes, assim como a largura, são variáveis, indo desde 0,5 a 1 $\mathrm{m}$ (Martin et al, 1980). No radargrama estes terraços começam ao longo do caminhamento em torno de $45 \mathrm{~m}$ e se estendem até aproximadamente $75 \mathrm{~m}$ de distância.

Após estes terraços, passamos com o GPR por um cordão-duna com altitude aproximada de 4 a $6 \mathrm{~m}$. O cordão-duna é constituído essencialmente por areias finas retrabalhadas pelo vento. As areias removidas pelo vento da face da praia, foram trapeadas pela vegetação herbácea de restinga adjacente à linha de preamar máxima. Esta vegetação, ao diminuir a velocidade do vento, causa a deposição das areias, dando origem ao cordão-duna. Neste sentido, o cordão-duna é uma duna estacionária. É importante salientar que para formação de um cordão-duna é necessário que a linha de costa permaneça estabilizada por um período de tempo relativamente longo (Accioly, 1997). 
Podemos notar também no radargrama, próximo ao cordão-duna, a presença de estruturas estratificadas características de deposição eólica, designadas por estratificações cruzadas. Chegando finalmente próximo ao mar, observamos que o sinal do radar vai gradativamente sendo atenuado devido a um aumento da salinidade. O lençol freático foi interpretado pela linha tracejada vermelha e com a linha tracejada de cor azul definiu-se a provável posição espacial do topo da cunha salina. Este limite entre a água doce e água salgada é conhecido como limite de Knorr.

A Figura 5 ilustra a obtenção do perfil realizado partindose próximo ao mar em direção ao continente, ou seja, com um sentido inverso ao sentido de aquisição do perfil Jacuípe 2.1, contudo, sem atravessar a área lagunar descrita na interpretação anterior.

No radargrama visto na Figura 6, dentro do limite da zona de infra-maré a qual fica exposta de modo sub aéreo, durante as marés baixas de sizígia, há uma grande atenuação dos refletores causada pela lavagem da água salgada. Indo em direção ao continente, atravessamos o cordão-duna e as areias litorâneas holocênicas. Tais ambientes apresentaram diversas estratificações cruzadas, e antigas paleo superfícies, devido ao retrabalhamento dessas dunas ao longo do tempo.

A Figura 7 mostra o caminho do GPR na aquisição do perfil Jacuípe 2.3 correspondente ao radargrama da Figura 8, onde foi possível identificar dois ambientes, 0 de areias litorâneas holocênicas e o cordão-duna. Interpretamos o forte refletor que aparece no radargrama como sendo o nível do lençol freático e pudemos observar feições estratigráficas nos dois ambientes. Temos o nível freático evidenciado no radargrama (Figura 8) pela linha tracejada de cor vermelha e também - limite de Knorr (linha tracejada de cor azul) destacando a cunha salina.

\section{Discussão e Conclusões}

A análise dos resultados obtidos permite uma visão em profundidade da sub superfície dos ambientes deposicionais costeiros sem grandes esforços e num curto período de tempo, com custos de aquisição relativamente baixos e uma resolução dos dados normalmente muito alta.

Os resultados obtidos neste trabalho foram considerados satisfatórios para detalhar aspectos geológicos e hidrológicos de ambientes deposicionais costeiros, particularmente de planícies costeiras. As imagens da sub superfície revelam espacialmente e também cronologicamente o sistema deposicional através da distribuição espacial das diferentes propriedades dielétricas.
Neste trabalho, realizamos perfís de praia com o GPR passando por ambientes como areias litorâneas pleistocênicas, terras úmidas, areias litorâneas holocênicas, cordão-duna e corpos areníticos expostos subaereamente. Analisando os radargramas obtidos, verificou-se a presença de uma cunha salina causando a atenuação do sinal do radar, e pode-se observar claramente um forte refletor nos radargramas registrados, sendo que o perfil da segunda aquisição revela a presença de um nível freático que evidencia o limite entre água doce e salgada (Limite de Knorr).

O perfil Jacuípe2.1 foi o que apresentou uma maior quantidade de informações acerca da subsuperfície, com ótima resolução das estruturas e camadas presentes. A continuação deste trabalho fará uma correlação entre os dados de GPR interpretados com dados provenientes de de perfis de poços geotécnicos.

\section{Referências}

Accioly, P. C. V., 1997. Evolução quaternária e dinâmica atual da planície costeira de Arembepe, Litoral Norte do Estado da Bahia.

Botelho, M. A. B., 2008. Manganese Prospection with Ground Penetrating Radar (GPR) in Bahia State - Brazil. GPR2008, P;1-6, Birmingham,UK.

Davis, J. L. \& Annan, A. P., 1989. Ground-penetrating radar for high-resolution mapping of soil and rock stratigraphy. Geoph. Prosp., 37: 531-551.

Ghignone,J.I. 1979. Geologia dos sedimentos fanerozóicos do estado da Bahia. In: Inda, H.A .V., org., Geologia e Recursos Minerais do Estado da Bahia; Textos Básicos. Salvador, SME/COM.

GSSI, 2005. RADAN 6.5 User's Manual. Geophysical Survey Systems, Inc, North Salem, NH, USA.

Martin, L., Carlos, A. S. P. B., Silva, G. V. B. \& Flexor, J. M., 1980. Mapa Geológico do Quaternário Costeiro do Estado da Bahia. Coordenação da Produção Mineral, Brasil.

Machado,S.L., Ribeiro, L.D.; Kiperstock, A .;Botelho, M. A B., e Carvalho, M.F., 2004. Diagnóstico da contaminação por metais pesados em Santo Amaro - BA, Revista de Engenharia Sanitária e Ambiental, V.9, No.2 : 140 - 155.

Ucha, J.M.; Botelho, M.A.B.; Vilas Boas, G.S.; Ribeiro, L.P. e Santana, P. S., 2002. Uso do Radar Penetrante no Solo (GPR) na Investigação dos Solos dos Tabuleiros Costeiros no Litoral Norte do Estado da Bahia. Rev. Bras. de Ciência do Solo, v.26, $n^{\circ}$ 02: 375-380. 
Figura 1 - Mapa de acesso ao local de estudo, a partir da cidade do Salvador.

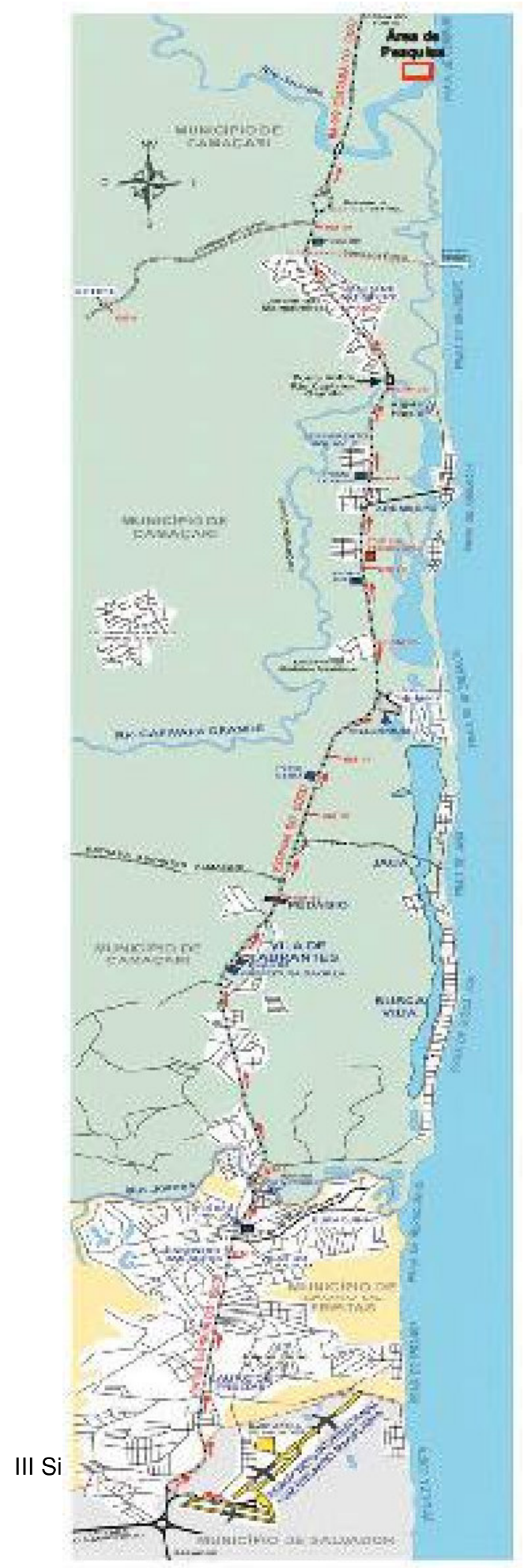



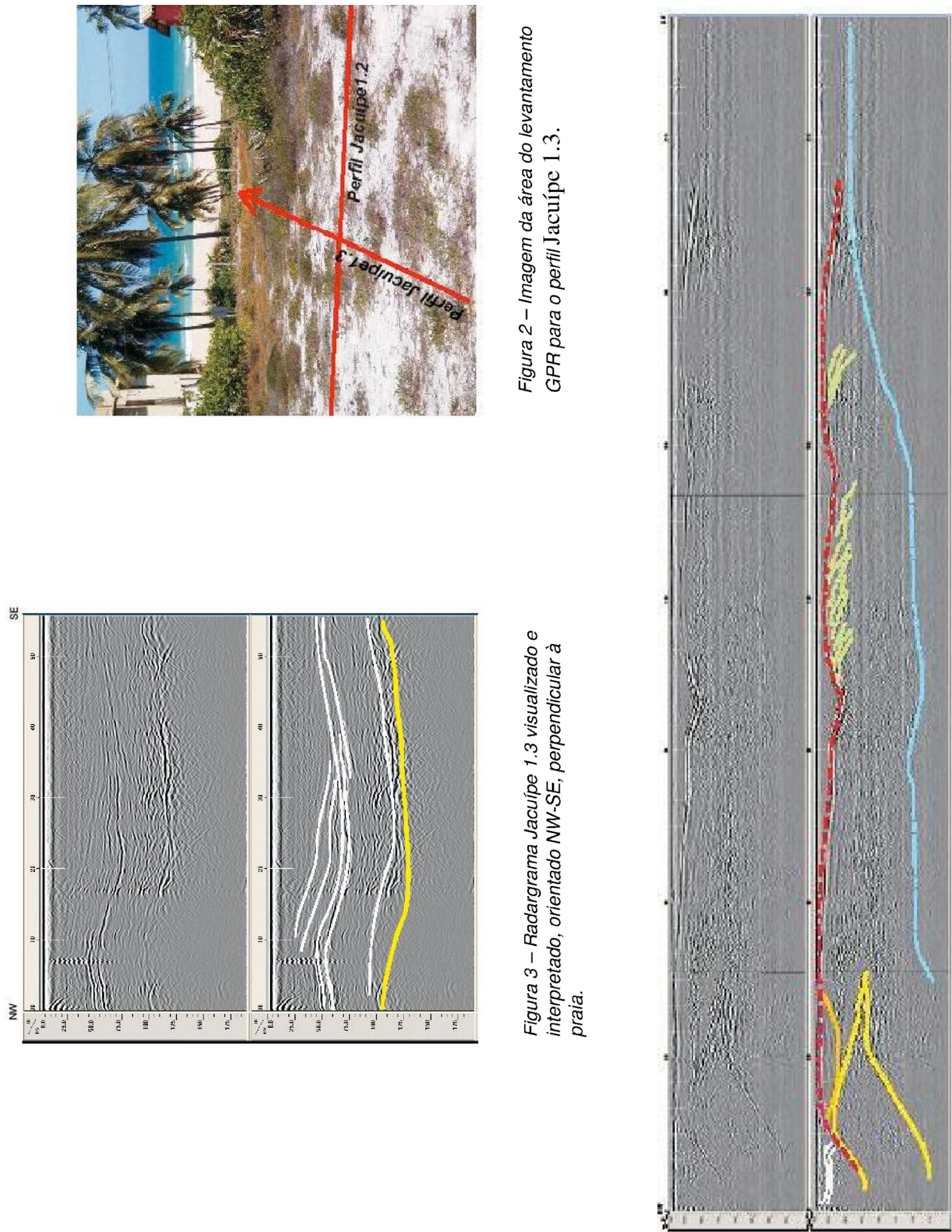

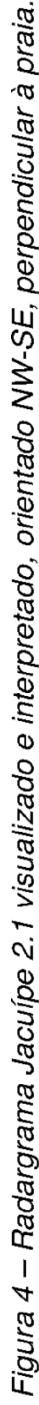

III Simpósio Brasileiro da SBGf - Belém 2008 


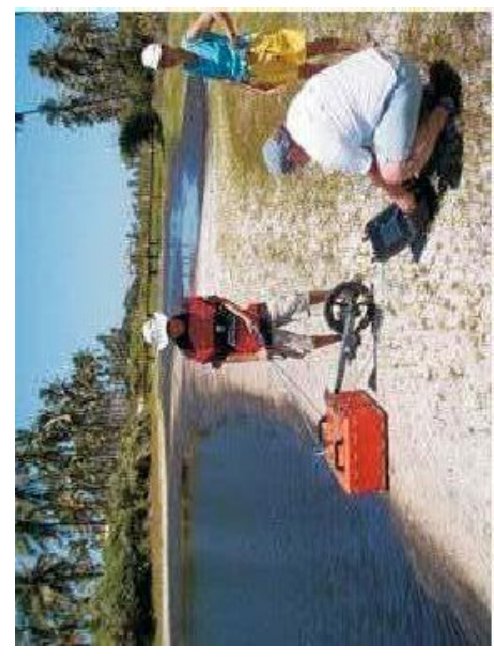

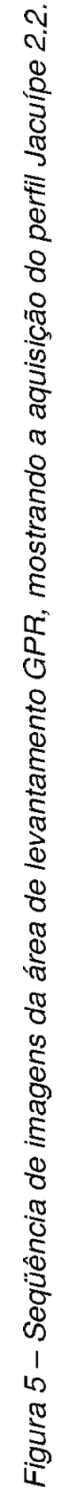

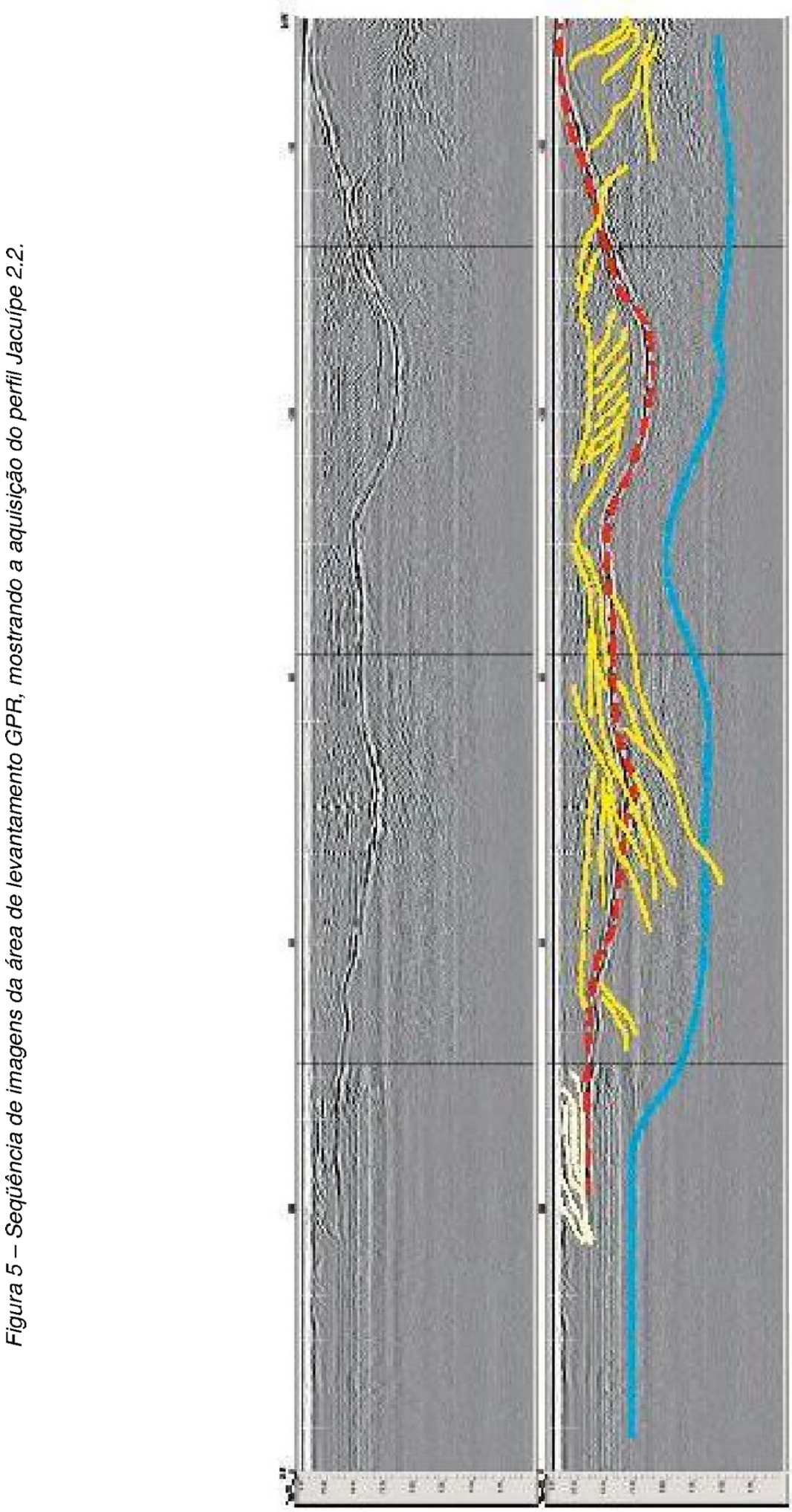

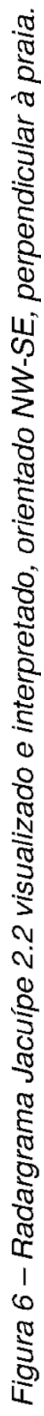

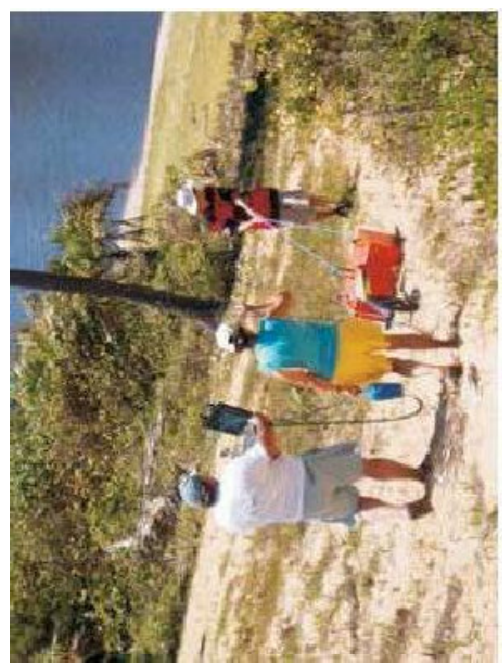

III Simpósio Brasileiro da SBGf - Belém 2008 

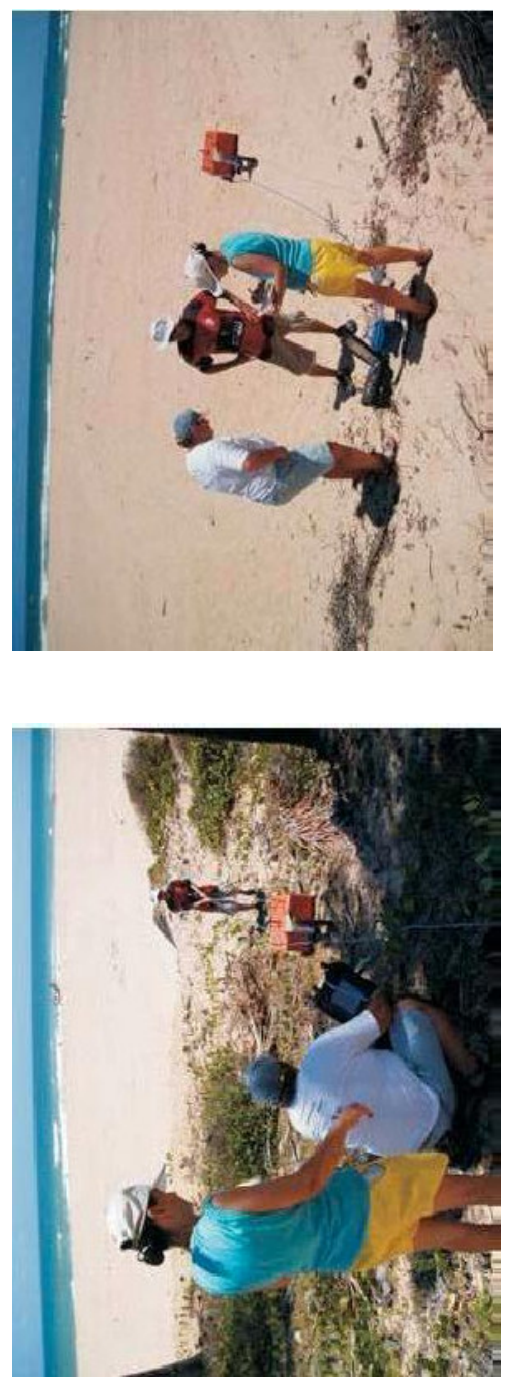

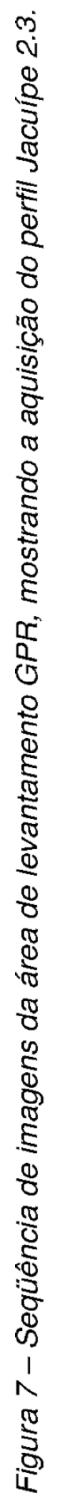

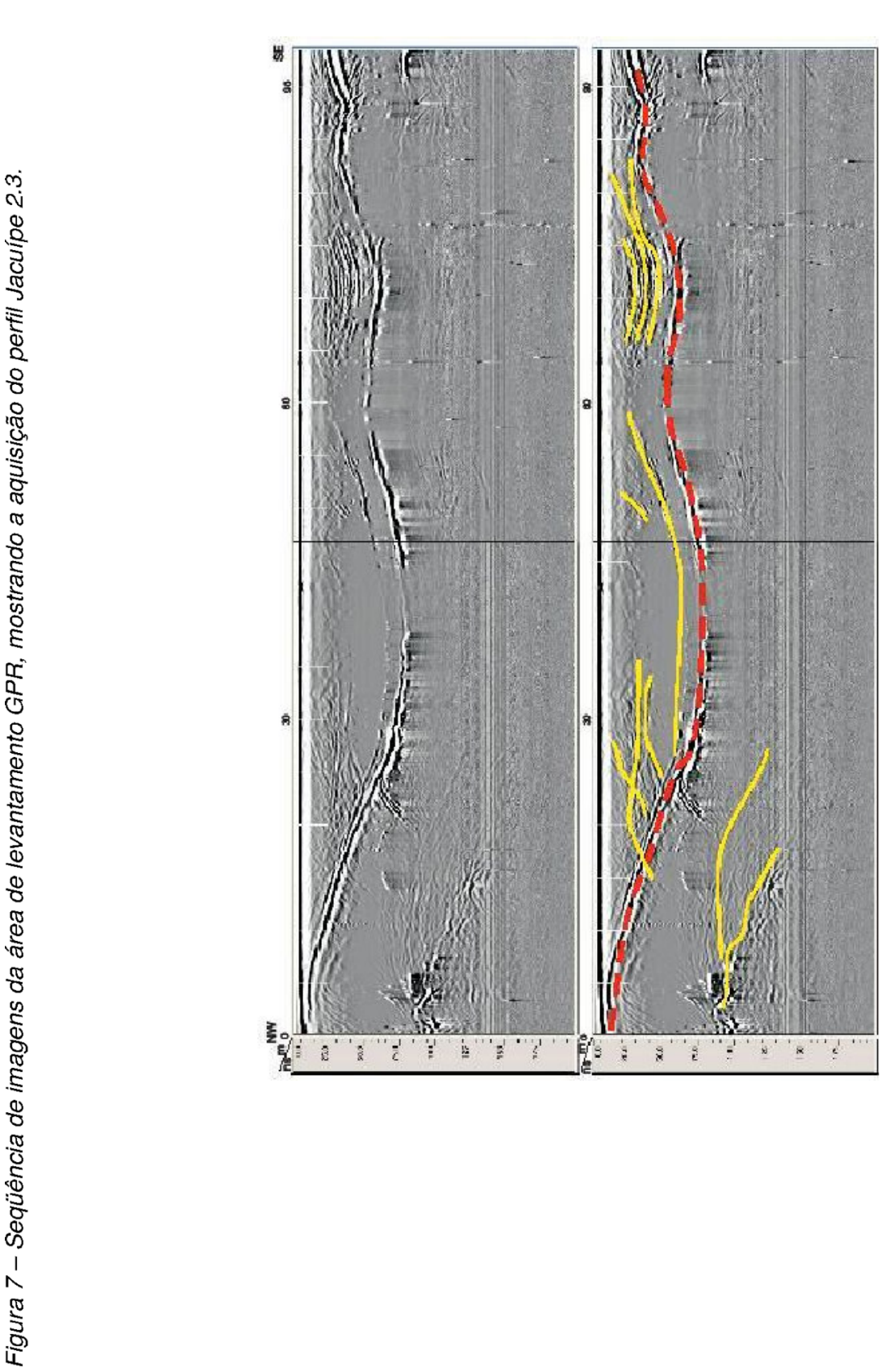

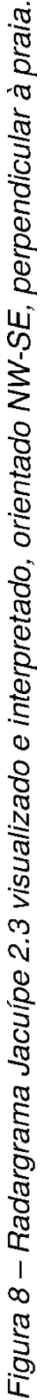

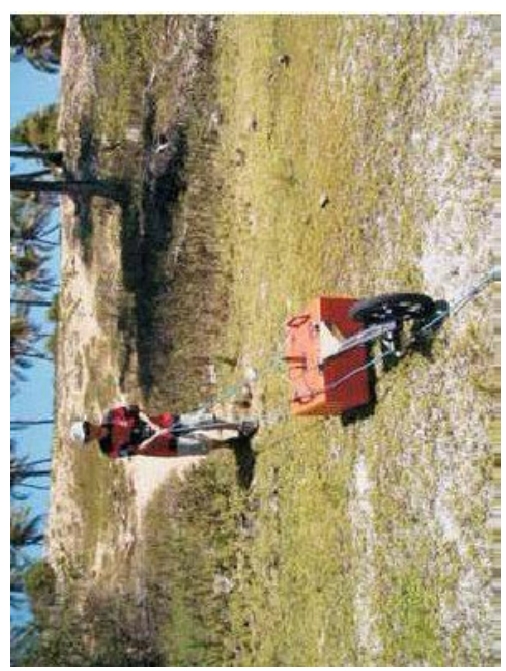

III Simpósio Brasileiro da SBGf - Belém 2008 